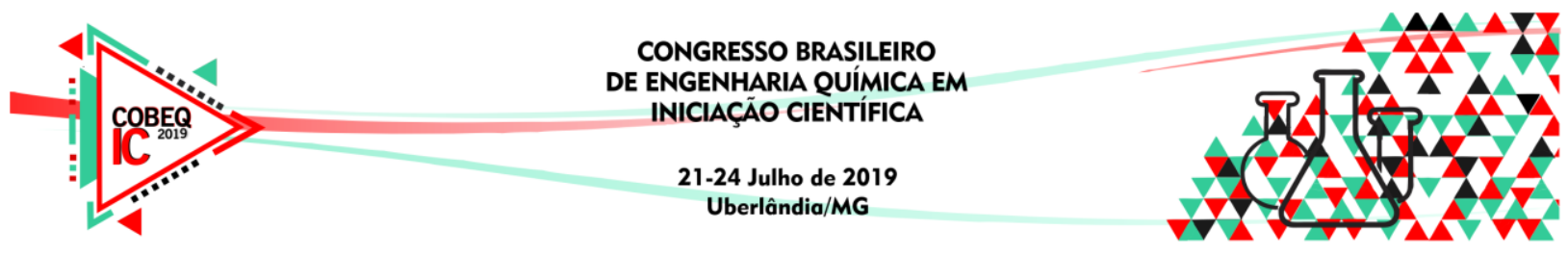

\title{
ANÁLISE EXPERIMENTAL E NUMÉRICA DA DINÂMICA DE PARTÍCULAS DE SOJA EM UM DISCO ROTATÓRIO
}

\author{
I.A. MORAIS ${ }^{1}$, POTENZA, F. ${ }^{1}$, R. M. LIMA $^{1}$, C. R. DUARTE ${ }^{1}$, M.A.S.BARROZO ${ }^{1}$ \\ ${ }^{1}$ Universidade Federal de Uberlândia, Faculdade de Engenharia Química \\ E-mail para contato: igor_almeidamorais@hotmail.com
}

\begin{abstract}
RESUMO - Devido à grande importância dos discos rotatórios em processos industriais envolvendo granulação e aos poucos dados presentes na literatura em relação ao equipamento, este trabalho tem como objetivo a compreensão da dinâmica de partículas no interior de um disco rotatório. Através de simulações numéricas e de dados experimentais, estudou-se a relação existente entre o grau de preenchimento, ângulo de inclinação e a velocidade de rotação, sendo possível ao final da análise encontrar uma equação para determinar a velocidade de centrifugação.
\end{abstract}

\section{INTRODUÇÃO}

Muito utilizada em processos industriais envolvendo fertilizantes, medicamentos e minérios (Chadwick et al., 2005), a granulação tem como objetivo o aumento no tamanho das partículas a partir da aglomeração de outras menores. Esse processo pode ser feito por dois meios: a via seca, quando não é utilizada nenhum tipo de solução e a agregação do pó é feita sob pressão; e via úmida, quando uma solução é utilizada com a finalidade de aglomerar as partículas (Couto et al., 2000).

Um dos equipamentos utilizados para a granulação por via úmida é o disco ou prato rotatório, caracterizado por um prato e uma borda lateral. Este conjunto executa um movimento rotação no seu próprio eixo, semelhante a um tambor rotatório e, além disso, pode ser inclinado de $0^{\circ}$ a $90^{\circ}$ em relação a horizontal, conforme apresentado na Figura 1. Em alguns casos o disco possui um raspador, com o intuito de evitar que o material se aglomere no fundo do equipamento.

Figura 1 - Detalhes do disco rotatório (Chadwick e Bridgwater, 1997).
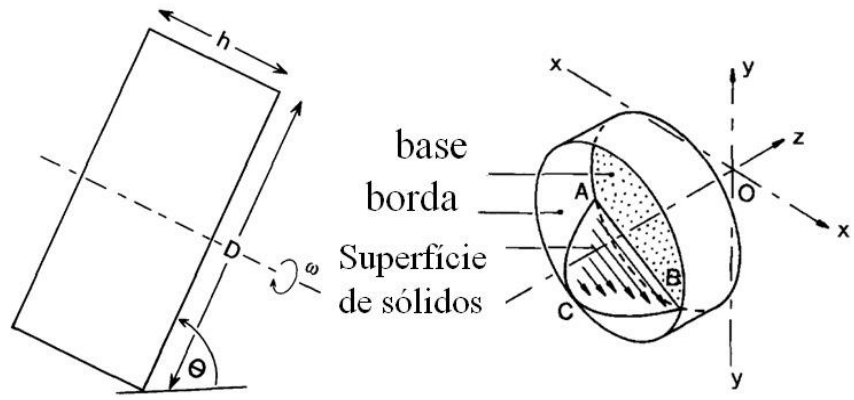


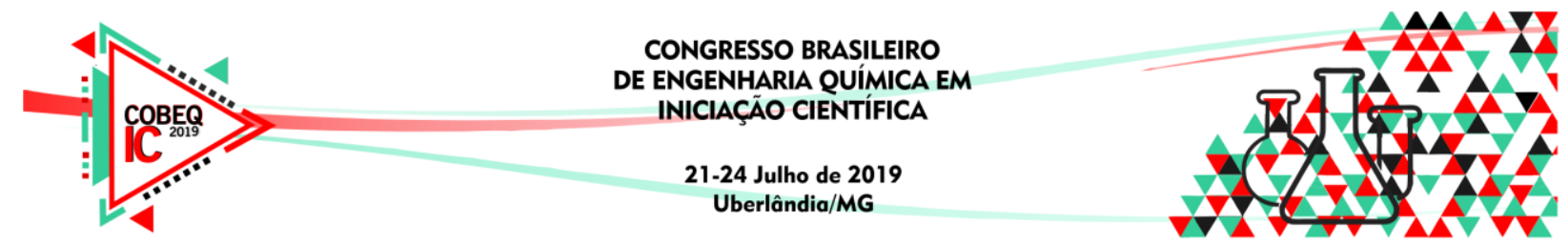

Durante o funcionamento as partículas podem apresentar regimes de rolamento, cascateamento, catarateamento e centrifugação (Chadwick et al., 2005), sendo cada um deles dependentes da dimensão do equipamento, velocidade de rotação, da inclinação do disco, do grau de preenchimento, das propriedades físicas do material granular e do coeficiente de atrito (Mellmann, 2001).

Chadwick e Bridgwater (1997) estudaram, para diferentes materiais granulares, a influência de geometria e da inclinação do equipamento nos regimes de escoamento. Chadwick et al. (2005) analisaram a retenção volumétrica de sólidos e o tempo de residência para um sistema contínuo, utilizando uma alimentação com até dois tamanhos de partículas.

Para auxiliar a compreensão de alguns fenômenos físicos, o Método dos elementos discretos (DEM) tem se destacado em pesquisas envolvendo comportamento de materiais granulares. A utilização do DEM se destaca por proporcionar a visualização de cada partícula, uma vez que o balanço de força é aplicado individualmente, assim, é possível a obtenção de dados como: velocidade, trajetória e as forças das partículas (Cundall e Strack, 1979).

A literatura possui poucos dados relativos ao disco rotatório, principalmente envolvendo simulações numéricas. Assim, este trabalho teve como objetivo a utilização do Método dos Elementos Discretos para verificar a influência da variação do ângulo de inclinação e do grau de preenchimento na transição dos regimes de escoamento em um disco rotatório.

\section{MÉTODO DOS ELEMENTOS DISCRETOS}

O método dos elementos discretos se alterna entre a segunda lei de Newton e a lei da Força-Deslocamento. A lei da Força-Deslocamento é usada para encontrar as forças de contato de deslocamento, enquanto a segunda lei de Newton fornece o movimento da partícula como resultado das forças que atuam sobre ela.

A segunda lei de Newton pode ser descrita conforme as equações 1 e 2.

$$
\begin{aligned}
& m_{i} \frac{d v_{i}}{d t}=\sum_{j} F_{i j} \\
& I_{i} \frac{d \omega_{i}}{d t}=\sum_{j} M_{i j}
\end{aligned}
$$

sendo $m_{i}, v_{i}, I_{i}$ e $\omega_{i}$ a massa, a velocidade linear, o momento de inercia e velocidade angular da partícula $i$, respectivamente, enquanto $F_{i j}$ e $M_{i j}$ são a força e o torque entre as partículas $i$ e $j$.

O modelo não linear mais comumente utilizado no DEM é uma combinação da teoria de Hertz (1882), em que é empregado o contato elástico entre duas partículas na direção normal, com a de Mindlin e Deresiewicz (1953), sem deslizamento, que descreve a força tangencial. Detalhes maiores sobre a modelagem podem ser encontrados no trabalho de Di Renzo e Di Maio (2004). 


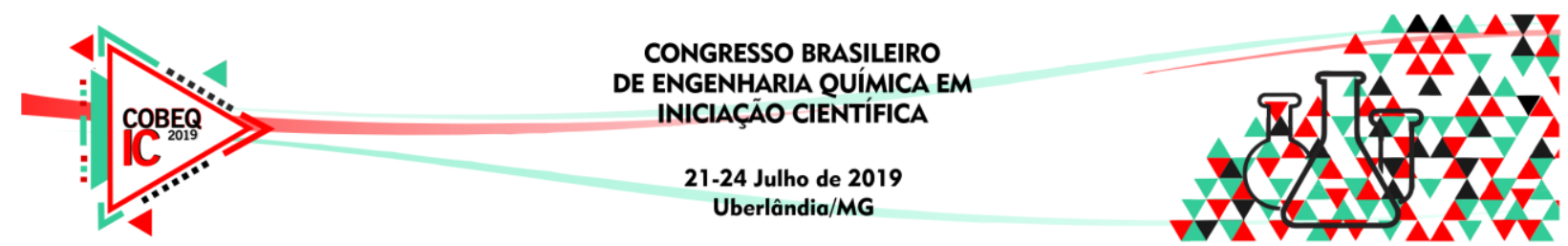

\section{MATERIAIS E MÉTODOS}

\subsection{Material granular e disco rotatório}

Os testes experimentais foram avaliados utilizando partículas de soja de diâmetro $6,39 \pm 0,04 \mathrm{~mm}$, com densidade de $1190 \pm 6 \mathrm{~kg} / \mathrm{m}^{3}$ e esfericidade 0,9 .

O equipamento utilizado foi um disco rotatório com $0,35 \mathrm{~m}$ de diâmetro e $0,20 \mathrm{~m}$ de borda, fabricado em aço inox. O disco apresenta uma inclinação regulável variando de $0-75^{\circ}$ conforme mostra Figura 2.

Figura 2 - Unidade Experimental
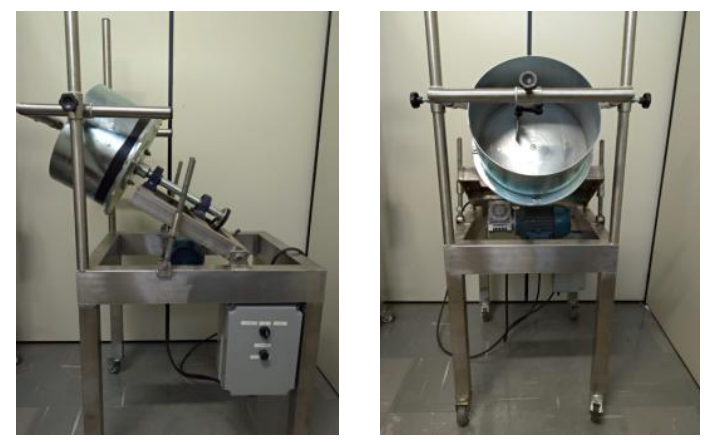

\subsection{Determinação da massa máxima}

Devido a abertura do disco, existe um limite de massa que pode ser utilizado no equipamento. Para a determinação desse limite foi adicionado uma grande quantidade de soja nos ângulos de inclinação (A.I.) de 40,45 e $50^{\circ}$ e nas velocidades de rotação (V.R.) de 5, 10, 20, 30 e $50 \mathrm{rpm}$, com intuito de verificar a influência dessas variáveis na massa máxima de soja presente no disco rotatório. Todas as medidas foram realizadas em triplicata.

\subsection{Metodologia numérica}

Uma vez efetuada as medições experimentais da massa máxima, realizou-se um planejamento $3^{\mathrm{k}}$, variando assim em três níveis o ângulo de inclinação do equipamento e o grau de preenchimento (G. P.), resultando assim em 9 simulações, conforme apresentado na Tabela 1. O objetivo foi verificar quais dessas variáveis influenciam na transição dos regimes de escoamento do disco rotatório. O grau de preenchimento foi determinado com base na menor massa máxima encontrada para cada ângulo.

Tabela 1 - Matriz de planejamento $3^{\mathrm{k}}$ utilizada nas simulações numéricas

\begin{tabular}{cccc}
\hline Níveis & -1 & 0 & 1 \\
\hline Ângulo $\left(^{\circ}\right)$ & 40 & 45 & 50 \\
G. P. $(\%)$ & 5 & 7.5 & 10 \\
\hline
\end{tabular}




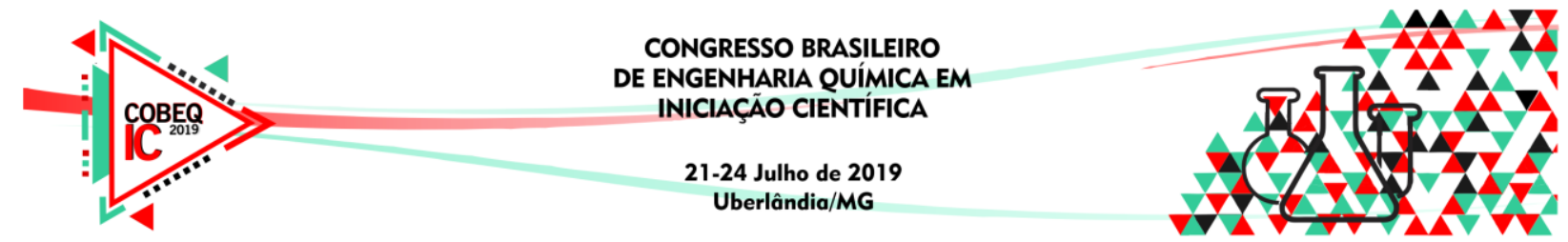

Todas as simulações foram conduzidas no software EDEM $^{\circledR} 3.0$ e foi utilizado o modelo de contato de Hertz-Mindlin. Para garantir a estabilidade numérica, utilizou-se um passo no tempo $1 \times 10^{-5}$ s equivalente a $20 \%$ do passo de tempo de Rayleigh.

A Tabela 2 apresenta de forma simplificada todas as condições utilizadas para a realização dos experimentos numéricos.

Tabela 2 - Condições utilizadas para a simulação.

\begin{tabular}{lccc}
\hline \multicolumn{1}{c}{$\begin{array}{c}\text { Modelo } \\
\text { Passo no Tempo (s) } \\
\text { Tamanho de Célula }\end{array}$} & & \multicolumn{2}{c}{ Hertz-Mindlin (noslip) } \\
$1 \times 10^{-5}$ \\
$3 \mathrm{R}_{\min }$
\end{tabular}

\section{RESULTADOS E DISCUSSÕES}

A Tabela 3 e a Figura 3 apresentam os resultados da massa máxima encontrado para cada combinação do ângulo de inclinação (A. I.) e velocidade de rotação (V. R.).

Tabela 3 - Massa máxima (Kg) possível em cada ângulo e velocidade de rotação.

\begin{tabular}{c|ccccc}
\hline A.I. $\left({ }^{\circ}\right) /$ V.R.(rpm) & 5 & 10 & 20 & 30 & 50 \\
\hline 40 & $5,79 \pm 0,05$ & $5,77 \pm 0,45$ & $6,97 \pm 0,13$ & $7,42 \pm 0,02$ & $9,37 \pm 0,05$ \\
45 & $4,43 \pm 0,02$ & $4,48 \pm 0,19$ & $5,05 \pm 0,19$ & $5,39 \pm 0,01$ & $6,65 \pm 0,06$ \\
50 & $3,88 \pm 0,02$ & $3,78 \pm 0,03$ & $4,19 \pm 0,11$ & $4,73 \pm 0,04$ & $5,09 \pm 0,03$ \\
\hline
\end{tabular}

Pela Tabela 3 e a Figura 3 percebe-se que o ângulo de inclinação e a velocidade de rotação são inversamente proporcionais, o aumento do ângulo resultou em uma diminuição da retenção de massa no disco rotatório, enquanto $o$ aumento da velocidade teve $o$ comportamento contrário. Destaca-se que as velocidades de 5 e $10 \mathrm{rpm}$ apresentaram resultados semelhantes, não havendo interferência da variável nesse caso.

Analisando a influência do ângulo de 40 para $50^{\circ}$ nota-se que ocorreu uma redução de $33,00 \%$ e $45,61 \%$ de massa para a velocidade de 5 e $50 \mathrm{rpm}$, respectivamente. Realizando a mesma análise para a velocidade de rotação, a elevação de 5 para $50 \mathrm{rpm}$ ocasionou um aumento de $61,65 \%$ no ângulo de $40^{\circ}$, já para o ângulo de $45^{\circ}$ foi somente de $31,20 \%$. Ângulos menores de inclinação possuem uma maior sensibilidade em relação a rotação do equipamento, esse fenômeno pode ser explicado porque quanto maior a quantidade de massa maior é a ação da força centrífuga pressionando as partículas na parede do disco rotatório e impedindo que as mesmas sejam expelidas. 


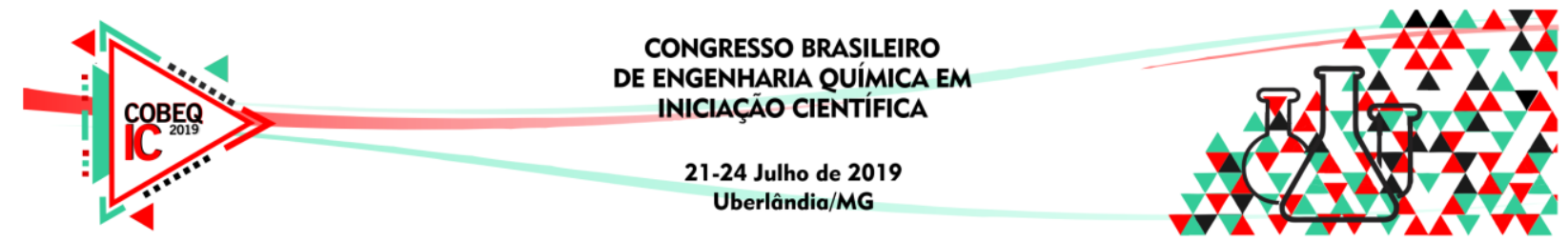

Figura 3 - Comportamento da variação da massa máxima em função do ângulo de inclinação e da velocidade de rotação.

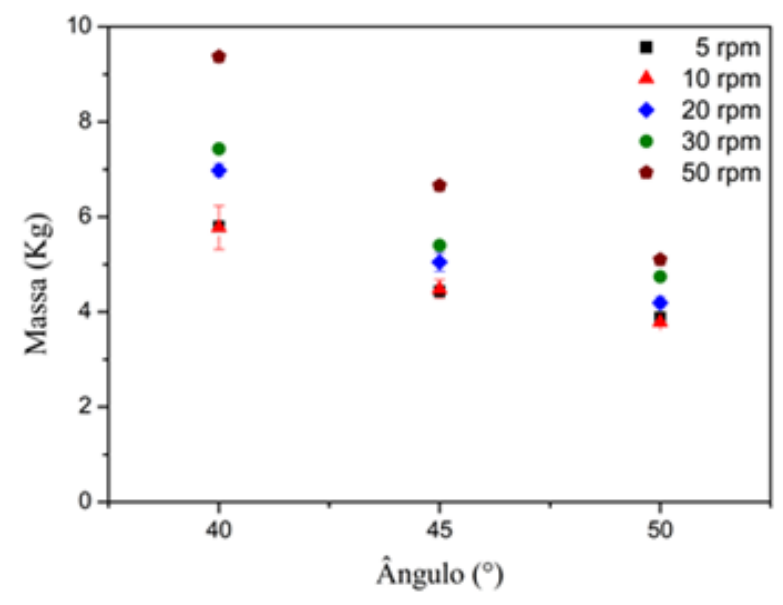

Com base na menor massa encontrada $(5,774,4,432$ e 3,781 $\mathrm{Kg}$ ) foram realizadas simulações numérica seguindo um planejamento $3^{\mathrm{k}}$, variando o grau de preenchimento em 5 , 7,5 e $10 \%$ e o ângulo de inclinação de 40,45 e $50 \mathrm{rpm}$, conforme já apresentado na Tabela 1. Como resposta para o planejamento foi utilizada a velocidade de rotação necessária para que atingisse os regimes de escoamento de centrifugação (V. C.). A Tabela 4 apresenta o resultado do planejamento $3^{\mathrm{k}}$.

Tabela 4 - Resultado do planejamento $3^{\mathrm{k}}$.

\begin{tabular}{ccc}
\hline $\begin{array}{c}\text { A. I. } \\
\left({ }^{\circ}\right)\end{array}$ & $\begin{array}{c}\text { G. P. } \\
(\%)\end{array}$ & $\begin{array}{c}\text { Vel. de Centrifugação } \\
(\mathrm{rpm})\end{array}$ \\
\hline 40 & 5,0 & 140,35 \\
45 & 5,0 & 290,31 \\
50 & 5,0 & 405,47 \\
40 & 7,5 & 99,09 \\
45 & 7,5 & 203,70 \\
50 & 7,5 & 337,11 \\
40 & 10,0 & 82,05 \\
45 & 10,0 & 149,80 \\
50 & 10,0 & 256,24 \\
\hline
\end{tabular}

A Tabela 5 apresenta efeitos significativos do planejamento $3^{\mathrm{k}}$. Pode-se observar que ambas as variáveis estudadas (ângulo de inclinação e o grau de preenchimento) apresentaram influência significativa na velocidade de centrifugação.

Tabela 5 - Sumário dos efeitos do planejamento $3^{\mathrm{k}}$.

\begin{tabular}{cccc}
\hline & A. I. & G. P. & Média \\
\hline Efeito & 112,89 & $-58,01$ & 218,24 \\
p-level & $<10^{-3}$ & 0,005 & $<10^{-3}$ \\
\hline \multicolumn{4}{c}{$\mathrm{R}^{2}=97,3 \%$} \\
\hline
\end{tabular}




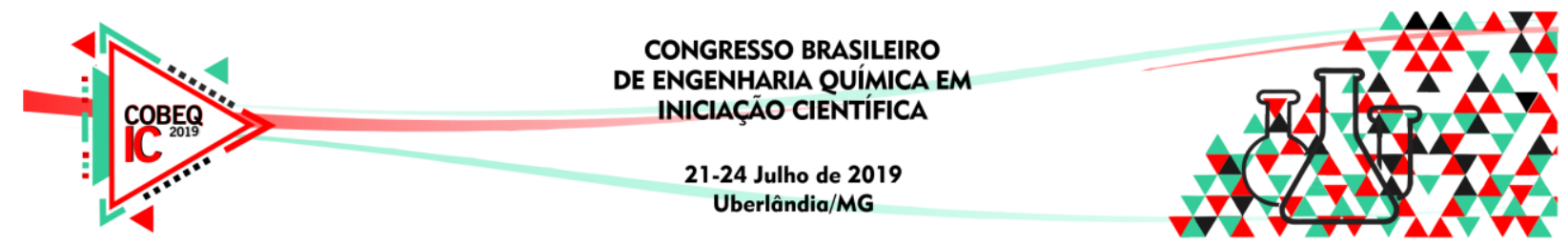

Realizando uma análise sobre efeitos das variáveis nota-se que elas possuem sinais opostos, ou seja, o aumento do ângulo de inclinação resulta em uma maior dificuldade da soja de atingirem a centrifugação, visto que foi necessária uma velocidade de rotação maior. Já o aumento do número de partículas antecipou a centrifugação. A Equação 3 apresenta o modelo normalizado proposto pelo planejamento, para um $\mathrm{R}^{2}$ de $97,3 \%$.

$$
\text { V.C. }=112,89 \text { A.I. }-58,01 G . P .+218,24
$$

\section{CONCLUSÃO}

A quantidade de massa máxima possível a ser utilizada no disco rotatório diminui com o aumento do ângulo de inclinação do equipamento. A velocidade de rotação teve um comportamento oposto a do ângulo, visto que a elevação da rotação aumentou a força centrifuga e consequentemente aumentou a retenção de partículas no disco rotatório.

O planejamento $3^{\mathrm{k}}$ demonstrou que tanto o ângulo de inclinação quanto o grau de preenchimento apresentaram uma influência significativa sobre a velocidade de centrifugação. A análise do planejamento comprovou que devido ao aumento do ângulo maior foi a velocidade de rotação necessária para a centrifugação, enquanto o grau de preenchimento teve o comportamento contrário, antecipando a centrifugação.

\section{REFERÊNCIAS}

CHADWICK, P. C.; BRIDGWATER, J. Solids flow in dish granulators. Chemical Engineering Science. v. 52, p. 2497-2509, 1997.

CHADWICK, P. C.; ROUGH, S. L.; BRIDGWATER, J. Holdup and residence time distributions in inclined dishes. Industrial and Engineering Chemistry Research. v. 44, p. 7529-7539, 2005.

COUTO, A.G.; GONZÁleZ ORTEGA, G.; PETROVICK, P.R. Granulação. Caderno de Farmácia. v.16, n. 1, p. 13-20, 2000.

CUNDALL, P. A.; STRACK, O. D. L. A discrete numerical model for granular assemblies. Géotechnique. v. 29, n. 1, p. 47-65, 1979.

MELLMANN, J. The transverse motion of solids in rotating cylinders-forms of motion and transition behavior. Powder Technology. v. 118, n. 3, p. 251-270, 2001.

DI RENZO, A.; DI MAIO, F. P. Comparison of contact-force models for the simulation of collisions in DEM-based granular flow codes. Chemical Engineering Science, v. 59, n. 3, p. 525-541, 2004. 